\title{
3D characterization of the fracture mechanisms of a Fe-rich Al-Si-Cu alloy
}

\author{
Angelika Brueckner-Foit ${ }^{1 *}$, Inigo Bacaicoa ${ }^{1}$, Martin Luetje ${ }^{1}$, Marcel Wicke ${ }^{1}$, Andreas Geisert ${ }^{2}$, and Martin Fehlbier ${ }^{2}$ \\ ${ }^{1}$ Institute for Materials Engineering, University of Kassel, D-34125 Kassel, Germany \\ ${ }^{2}$ Chair of Foundry Technology, University of Kassel, Kurt-Wolters-Strasse 3, D-34109 Kassel, Germany
}

\begin{abstract}
The effect of the defect size and morphology on the fatigue damage evolution was analysed in a recycled $\mathrm{Al}-\mathrm{Si}-\mathrm{Cu}$ alloy by micro-computed tomography and scanning electron microscopy. Fatigue tests were performed and the different crack initiation scenarios were characterized and classified. The interaction between shrinkage and gas pores was the key crack initiation mechanism and the $\mathrm{B}-\mathrm{A} 15 \mathrm{FeSi}$ particles did not play any role in the crack initiation phase. However, crack path analysis indicated that there is a certain amount of crack advance by brittle fracture of the $\beta$-phase particles. This is in accordance with the findings of tensile tests in which the ductility depended strongly on the iron content.
\end{abstract}

\section{Introduction}

Cast Al-Si-Cu alloys are extensively used in the aeronautic and automotive industry as they provide with excellent mechanical properties, castability and recycling possibilities [1,2]. The use of the recycled grade alloy as base material implies a significant reduction of $\mathrm{CO}_{2}$ emission and process costs since the manufacturing of recycled aluminum requires only $5 \%$ of the energy in comparison with the primary alloy [3]. Nevertheless, the use of recycled aluminum for structural components can lead to the premature failure of the components if the stress state includes certain amount of cycling loading. This is the fundamental idea motivating the investigations carried out in recent years about the characterization of cast defects in recycled Al-Si alloys $[4,5]$ and their influence on the fatigue damage $[6,7]$.

The presence of iron in the cast melt causes the formation of brittle iron rich intermetallic inclusions that promotes the formation of shrinkage pores and reduces the tensile properties of the alloy [8]. Previous studies report that the iron inclusions do not have a direct effect on crack initiation since cracks tend to initiate from large shrinkage pores or small interacting gas pores [9]. However, the influence of the Fe-rich particles on the damage evolution for different defect scenarios requires further investigation in order to ensure the safety and reliability of structural parts. Moreover, non-equilibrium heat treatments can fragment and dissolve the iron rich compounds, and hence significantly improve the ultimate strength and the ductility of the alloy [10].

The effect of heat treatment on the crack initiation is limited due to the presence of large shrinkage pores but its influence on the crack propagation mechanisms is yet unknown.

In this study, fatigue tests were performed and the fracture surfaces were analyzed by scanning electron microscopy and micro-computed tomography in order to characterize the effect of the interaction between the $\mathrm{Fe}$ rich phase and the various pores on the fatigue damage evolution. The effect of the Fe content is studied by systematically varying the iron content of the alloy and relating the damage mechanism to the three-dimensional morphology and disposition of defect structures obtained by computed-tomography scans and in the scanning electron microscope.

\section{Material and experimental methods}

Table 1 shows the chemical composition of the Fe-rich near-to-eutectic $\mathrm{Al}-\mathrm{Si}-\mathrm{Cu}$ alloy used in the present work. The Fe-content was varied adding different amounts of iron in the cast melt, as shown in table 1 . The specimens were cast by gravity die casting at $760^{\circ} \mathrm{C}$ in a steel mold pre-heated at $350^{\circ} \mathrm{C}$ achieving a fixed cooling rate with a certain dispersion. The specimens were die cast without additional machining in order to consider the effect of the casting skin, since it has been recently reported that the casting skin can insulate the casting defects from the air environment and promote sub-surface crack initiation [9].

The Mn:Fe relationship is 0.28 , which can promote partial substitution from $\mathrm{B}-\mathrm{Al}_{5} \mathrm{FeSi}$ to the less detrimental $\alpha-\mathrm{Al}_{15}(\mathrm{Fe}, \mathrm{Mn})_{3} \mathrm{Si}_{2} \quad[11], \quad$ although a significant amount of $B$-phase is formed. 


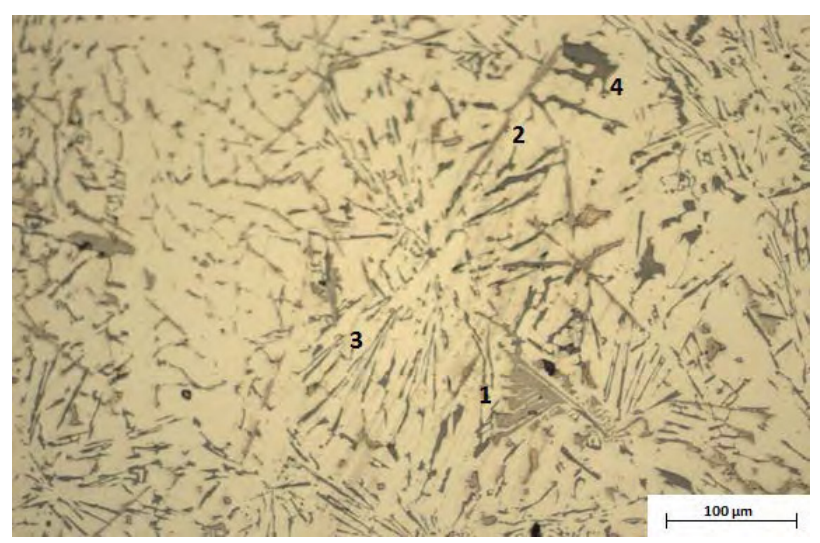

Fig. 1 Main inclusions of recycled Al-Si-Cu alloy: 1- $\alpha-$ $\mathrm{Al}_{15}(\mathrm{FeMn})_{3} \mathrm{Si}_{2}, 2-\beta-\mathrm{Al}_{5} \mathrm{FeSi}, 3$ - Euectic silicon, 4- $\mathrm{CuAl}_{2}$

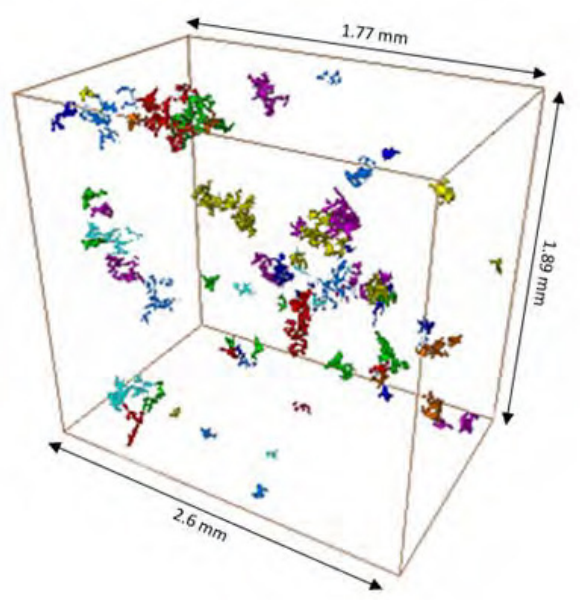

Fig. 2 3D reconstruction of the typical shrinkage pores in the studied alloy.

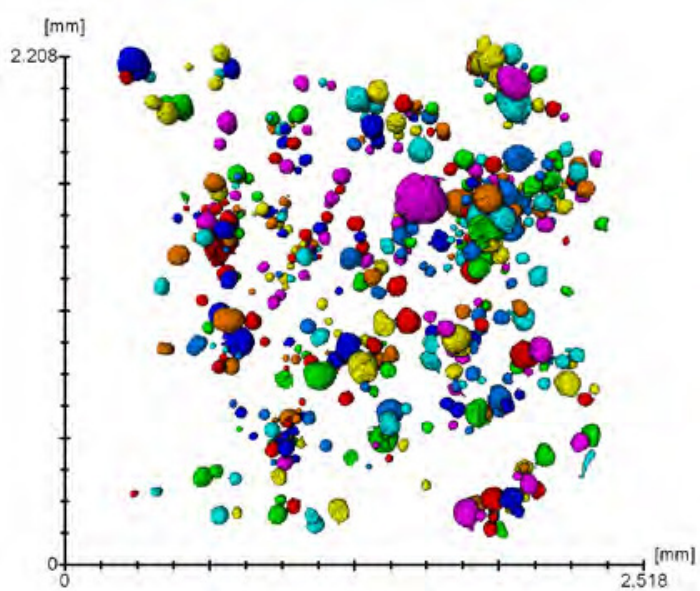

Fig. 3 3D reconstruction of the typical gas pores in the studied alloy.

The studied alloy is characterized by the eutectic silicon particles, Fe-rich inclusions and $\mathrm{Cu}$-rich compounds, which can be observed in Fig. 1. The Chinese-script-like $\alpha$-phase and the platelet-like $\beta$-phase are the main iron rich inclusions present in the alloy. The brittleness of $\beta$ -
$\mathrm{Al}_{5} \mathrm{FeSi}$ plates and their tendency to form large clusters of particles significantly reduce the ductility and the ultimate strength of the alloy [10]. Some specimens were subjected to heat treatment at a solution temperature of $525^{\circ} \mathrm{C}$ and solution time 2 hours in order to investigate the influence of heat treatments on the microstructure and the fatigue damage evolution of the material. Fig. 2 shows volume elements with a high concentration of shrinkage and Fig. 3 the typical gas pores formed during the cooling phase of the casting process. Volume elements with different porosity levels were obtained as a result of the variability of the casting parameters.

Specimens with different $\mathrm{Fe}$-content were tensile tested in a MTS E45 testing machine at a strain rate of 1.5 10-4 $\mathrm{s}-1$. The fatigue tests were performed at different stress levels at $\mathrm{R}=-1$ and $50 \mathrm{~Hz}$ and the fracture surfaces were subsequently analyzed by scanning electron microscopy and micro-computed-tomography with the aim of classifying the different fracture damage scenarios.

A high resolution lab computer tomograph (Zeiss Xradia Versa 520) was used for three-dimensional measurements of the casting defects at $70 \mathrm{KV}$ and a power of $7 \mathrm{~W}$ with the $0.4 \mathrm{X}$ objective, achieving a resolution of $3.84 \mu \mathrm{m} /$ voxel for the pores segmentation and $2.89 \mu \mathrm{m} /$ voxel for Fe-rich inclusions. The image analysis was carried out with the rendering software Avizo [12], in which the casting pores were segmented by adjusting grey scale after applying the non-local means filter, whereas the Fe-rich inclusions were segmented manually. 
Table 1 Chemical compositions of the Al-Si-Cu alloy with different Fe-additions (wt. \%).

\begin{tabular}{cccccccc}
\hline Alloy & $\mathbf{S i}$ & $\mathrm{Cu}$ & $\mathbf{M g}$ & $\mathrm{Fe}$ & $\mathrm{Zn}$ & $\mathrm{Mn}$ & $\mathrm{Al}$ \\
\hline $\mathrm{A}$ & 12.96 & 1.52 & 0.68 & 0.6 & 0.48 & 0.17 & rest \\
B & 12.87 & 1.64 & 0.58 & 1.37 & 0.47 & 0.23 & rest \\
C & 12.99 & 1.8 & 0.43 & 1.85 & 0.51 & 0.3 & rest \\
D & 12.62 & 1.45 & 0.51 & 2.28 & 0.45 & 0.26 & rest \\
\hline
\end{tabular}

\section{Experimental results}

\subsection{Fatigue behaviour}

Fig. 4 shows the results of the fatigue tests performed with the previously described specimens. The large scatter in the fatigue life at each stress amplitude level indicates the strong influence of the casting defects on the fatigue as well as the high variability of the morphology of defects associated with this casting process. An exhaustive analysis of the fracture surfaces both by scanning electron microscopy and microcomputed tomography revealed that there are distinct failure behaviors related to different fatal defects.

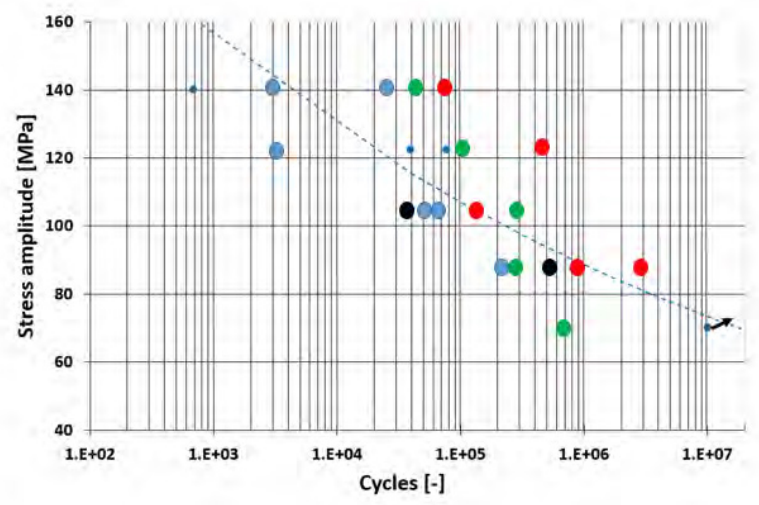

Fig. 4 Fatigue curve of die cast specimens; classification according to fracture origin; red circles: gas pores, green circles: interior and subsurface shrinkage pores, blue circles: interaction between gas pores and shrinkage pores, black circles: crack initiation from $\mathrm{MgO}$ inclusions on surface; small symbols: surface damage or non-identified fracture origin.

Cracks tend to initiate from gas pores located close to the surface in the cases in which large shrinkage pores are absent and the gas pores are located close to the surface (see Fig. 5). The variability of the cooling rate during the casting process increased the dispersion of the size of shrinkage pores. Under unfavorable conditions, specimens were cast with giant shrinkage pores of around $1 \mathrm{~mm}$ (see Fig. 7).
Nevertheless, the drop on lifetime was not dramatic in these cases and a substantial amount of internal flaw extension occurred prior to failure.

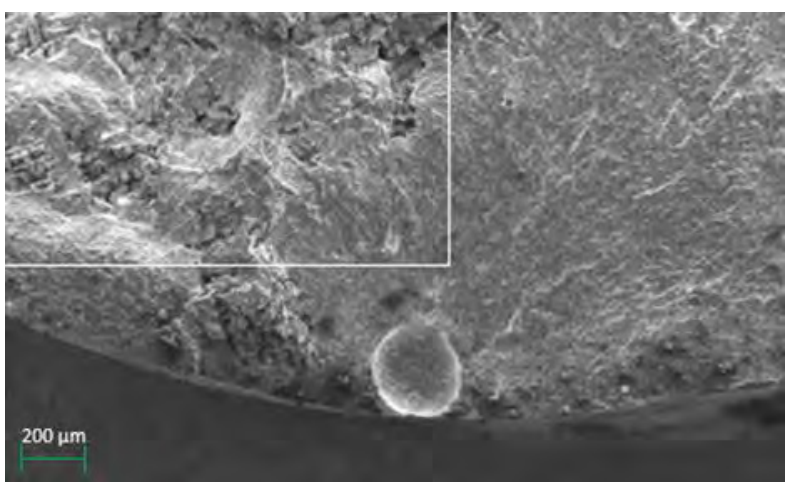

Fig. 5 Fracture surface of specimen failed at $140 \mathrm{MPa}, 74,283$ load cycles.

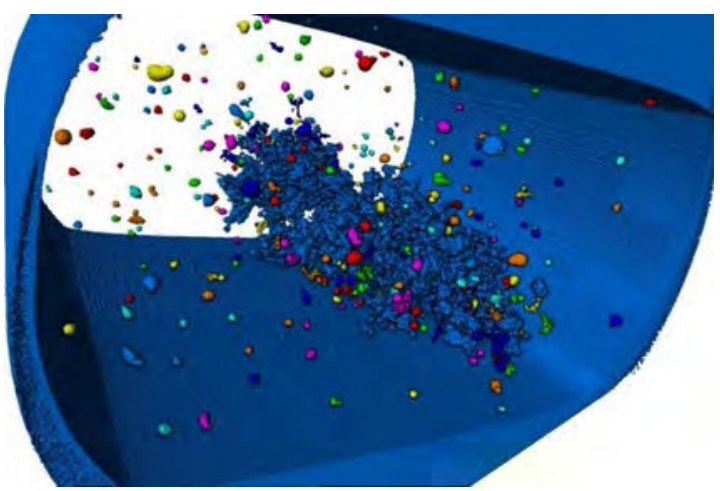

Fig. 6 Sample containing typical gas and shrinkage pores.

Interaction between defects was the most common scenario, what led to the premature failure of the specimens. This phenomenon can be explained by the fact that gas pores tend to agglomerate around shrinkage pores in the interdendritic structures (see Fig. 6 and Fig. 7). Furthermore, multiple crack initiation is likely to happen as a result of the intricate spatial pattern of bifurcations and branches of typical shrinkage pores (see e.g. Fig. 2). 


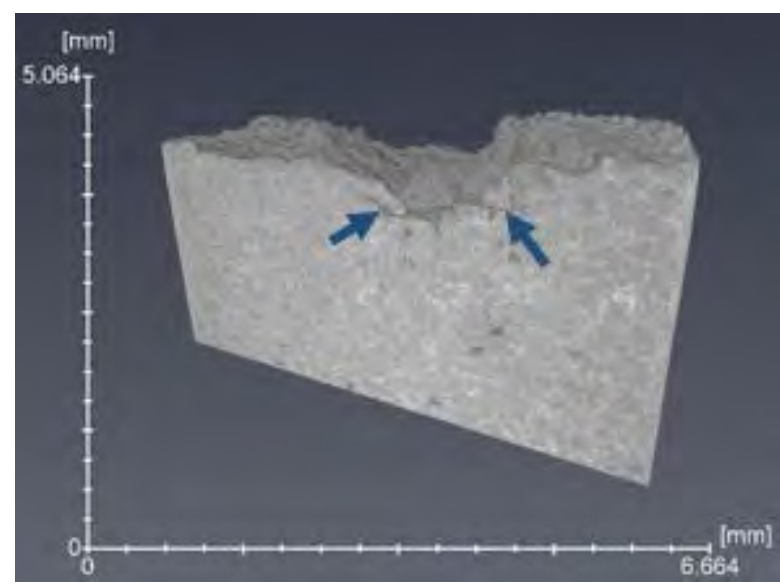

Fig. 7 Fracture surface of specimen failed at $140 \mathrm{MPa}, 45,065$ load cycles; large shrinkage pore with rough fracture surface and secondary cracks (blue arrows).

\subsection{Effect of the Fe-rich inclusions}

The $\mathrm{B}-\mathrm{Al}_{5} \mathrm{FeSi}$ particles form large three-dimensional clusters (see Fig. 8), but they did not had a significant influence on crack initiation. These clusters are embedded flaws, as there are no iron inclusion in the surface or subsurface regions (see. Fig. 9). No direct influence of the $\mathrm{B}-\mathrm{Al}_{5} \mathrm{FeSi}$ particles was observed in the SEM analysis of the fracture surfaces. This is in agreement with the fact that a higher concentration of these particles was observed in the inner part of the specimen; and therefore they have a limited effect on the crack initiation.

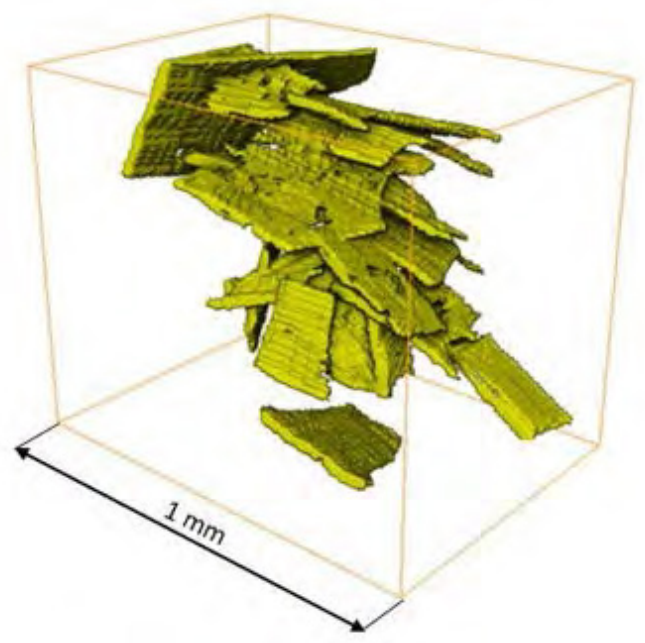

Fig. $83 \mathrm{D}$ reconstruction of a $\mathrm{B}-\mathrm{Al}_{5} \mathrm{FeSi}$ inclusion cluster.

Agglomeration of complex clusters of inclusions distributed along the specimens can be observed in the $3 \mathrm{D}$ reconstructions of the $\mathrm{B}-\mathrm{Al}_{5} \mathrm{FeSi}$ particles. Therefore, the inclusions that are depicted as individual needle-like particles in the 2D metallographic images may actually belong to a larger composite inclusion consisting of an agglomerate of plate-like particles.
The fracture profiles of the fatigue tests were examined on sections perpendicular to the fracture surface in the optical microscope and scanning electron microscope. This approach enables to examine if other microstructural features were involved in the evolution of the fatigue damage and if the crack development was driven by the fracture or the debonding of the $\beta-\mathrm{Al}_{5} \mathrm{FeSi}$ and the eutectic Si particles.

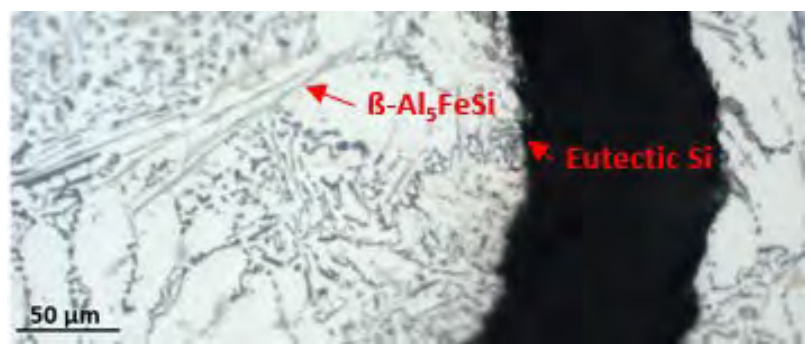

Fig. 9 Fracture surface cross section of a fatigue specimen at $122 \mathrm{MPa}$ and 39,122 cycles.

Fig. 9 shows an example of the cross sectional fracture surface of fatigue specimen. It can be observed that a large cluster of $\mathrm{B}-\mathrm{Al}_{5} \mathrm{FeSi}$ inclusions is located close to the crack path, and that the crack path follows the eutectic Si particles without breaking the cluster of the $\beta$ phase inclusions. This is related to the fact that the preferred orientation of these inclusions is perpendicular to the crack path in this particular case. However, cleavage fracture of a $\mathrm{B}-\mathrm{Al}_{5} \mathrm{FeSi}$ particle can be observed in another area of the cross sectional fracture surface in the same fatigue specimen (see Fig. 10). Here, the platelike morphology of the $\beta-\mathrm{Al}_{5} \mathrm{FeSi}$ inclusion causes the kinking of the crack path at the edges of the particle.

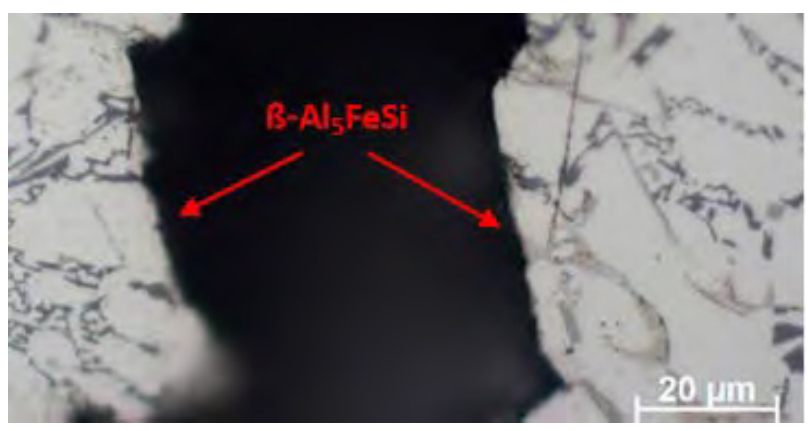

Fig. 10 Cleavage fracture of a $\beta-\mathrm{Al}_{5} \mathrm{FeSi}$ plate in the cross section of a fatigue specimen.

Fig. 11 shows the kinking of the crack path as a result of cleavage fracture of hard intermetallic particles. It can be observed that the $\mathrm{B}-\mathrm{Al}_{5} \mathrm{FeSi}$ platelets split right through the middle and drive the local direction of crack. The crack growths to the end of the $\mathrm{B}-\mathrm{Al}_{5} \mathrm{FeSi}$ platelets, until it reaches the aluminum matrix that allows the relaxation at the crack tip by local plastic flow due to its ductility. It can also be observed $\mathrm{Cu}$-rich particles located parallel have a similar effect on the crack path. 


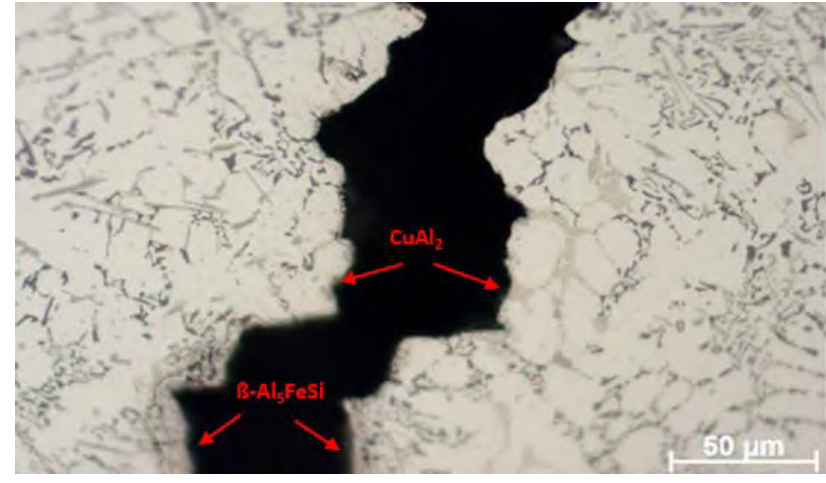

Fig. 11 Crack path in the cross sectional fracture surface of a fatigue specimen.

Fig. 12 shows the cross sectional fracture surface of a fatigue specimen in which the rupture of an entire $\beta-\mathrm{Al}_{5} \mathrm{FeSi}$ occurred. It can be observed that the crack propagated breaking various Fe-rich particles belonging to the same cluster. In this case the particles also broke through the middle at different levels of the cluster (see Fig. 8). The connection of the $\mathrm{B}_{3} \mathrm{Al}_{5} \mathrm{FeSi}$ plates in different plains leads to the kinking of the crack path. Besides the plate-like $\beta-\mathrm{Al}_{5} \mathrm{FeSi}$ particles, broken Chinese-script $\alpha$ $\mathrm{Al}_{15}(\mathrm{Fe}, \mathrm{Mn})_{3} \mathrm{Si}_{2}$ inclusions were also observed in the crack path at the cross sectional fracture surface of the fatigue specimen (see Fig. 13).

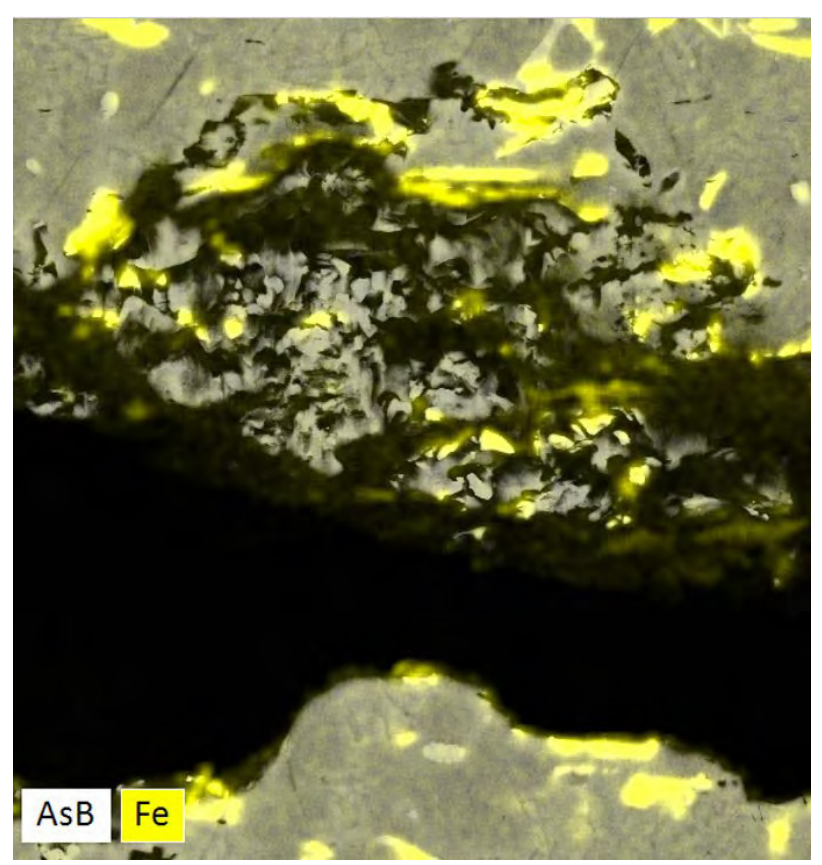

Fig. 12 SEM cross sectional fractograph of a fatigue specimen with a broken $\mathrm{B}-\mathrm{Al}_{5} \mathrm{FeSi}$ cluster.

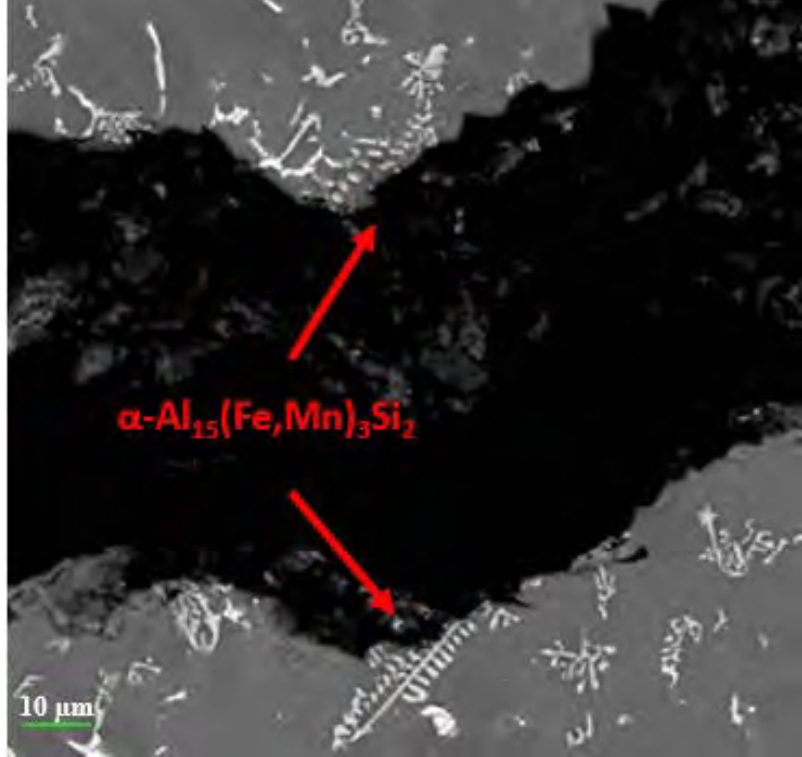

Fig. 13 Cleavage fracture of a Chinese-script like $\alpha$ $\mathrm{Al}_{15}(\mathrm{Fe}, \mathrm{Mn})_{3} \mathrm{Si}_{2}$

\subsection{Effect of heat treatment}

The $\beta-\mathrm{Al}_{5} \mathrm{FeSi}$ did not have a direct influence on the crack initiation process since damage initiated from the big shrinkage pores or interacting gas pores, therefore the effect of heat treatment on fatigue life is limited. However, the non-equilibrium heat treatments with solution temperature at $525^{\circ} \mathrm{C}$ during $2 \mathrm{~h}$ led to a significant level of fragmentation and dissolution of the $\beta-\mathrm{Al}_{5} \mathrm{FeSi}$ particles, what improved notably the ultimate strength and ductility of the alloy (see Fig.15). The addition of $\mathrm{Fe}$ in the alloy caused an exponential increase in the size of the $\mathrm{B}-\mathrm{Al}_{5} \mathrm{FeSi}$ inclusions (see Fig. 12) that decreased the elongation at break of the alloy. Heat treatments also improved the mechanical properties of the modified alloy, although the effect diminished with increasing Fe content.

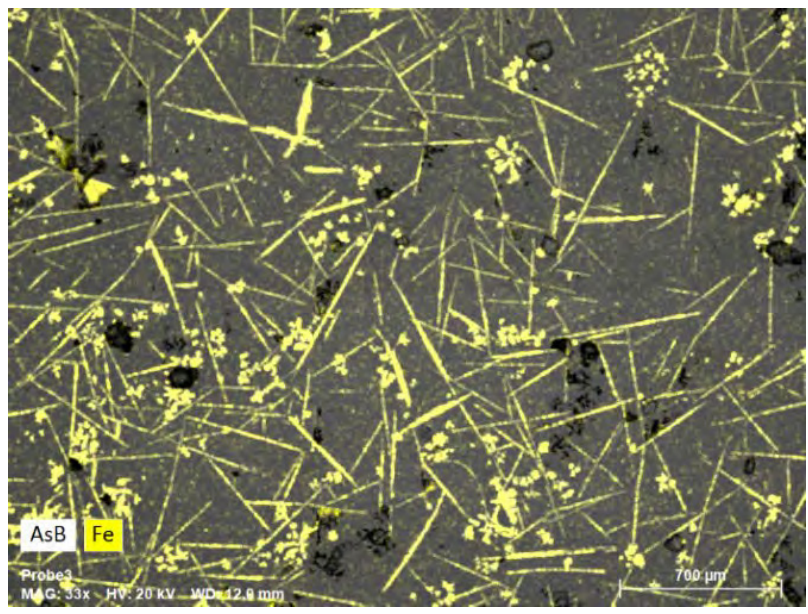

Fig. 13 Massive brittle $\beta-\mathrm{Al}_{5} \mathrm{FeSi}$ plates in the alloy with 2.3 $\mathrm{Fe} \%$ (D) 
The fracture surface analysis shows the cleavage fracture of massive $\mathrm{B}_{-} \mathrm{Al}_{5} \mathrm{FeSi}$ plates together with some fractured $\mathrm{Cu}$-rich particles (see Fig. 13). The observation of the cross sectional fracture surfaces also reveals the dominating fracture mechanism. Fig. 14 shows two fractured $\mathrm{B}-\mathrm{Al}_{5} \mathrm{FeSi}$ inclusions that have been split through the middle at the rupture of the specimen. The difference on the orientation of the broken plates causes the formation of sharp angles in the fracture surfaces.

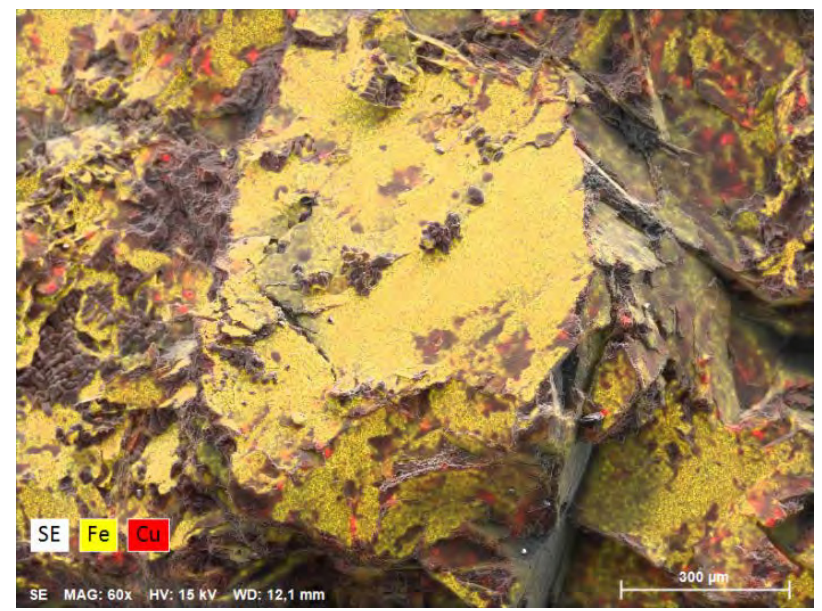

Fig. 14 Cleavage fracture of a massive $\mathrm{B}-\mathrm{Al}_{5} \mathrm{FeSi}$ inclusion in the alloy with $2.3 \% \mathrm{Fe}$ content (D) together with some $\mathrm{Cu}$-rich particles.

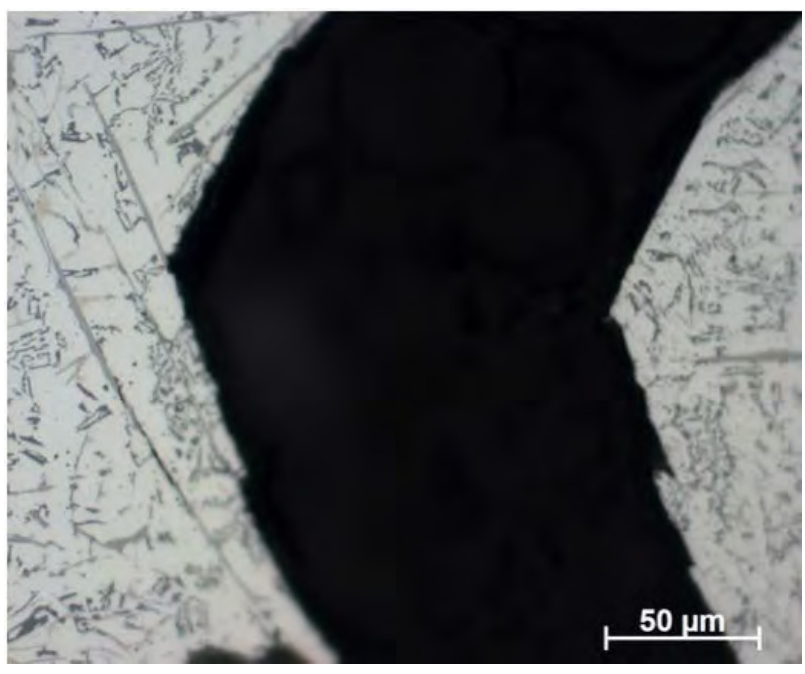

Fig. 15 Cross section of the fractured specimen with $2.3 \% \mathrm{Fe}$ content.

In the heat-treated specimen with high Fe-content the main fracture mechanism was the cleavage of $\beta-\mathrm{Al}_{5} \mathrm{FeSi}$ inclusions that were not able to fragment and dissolve during the heat treatment. Nevertheless, it can be observed that the fracture mechanism was not fully dominated by the rupture of the Fe-rich inclusions, but the fracture of the eutectic Si particles (see Fig. 16).
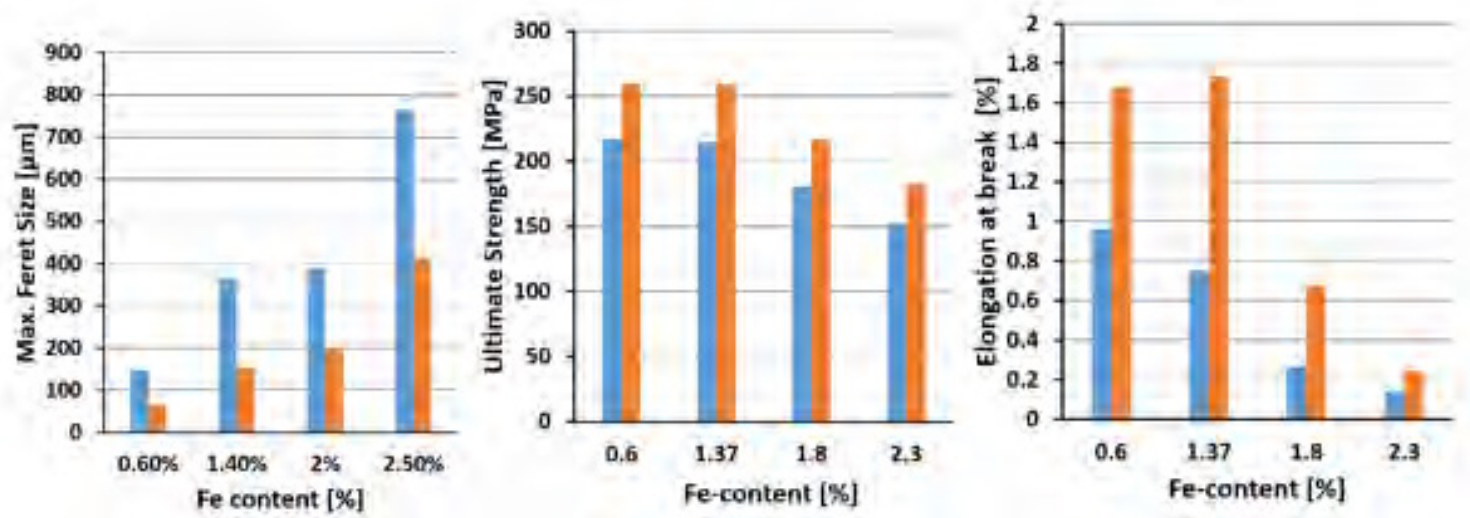

Fig. 16 Influence of the Fe content before (blue) and after (orange) heat treatment on: a) max. Feret size of the Fe-rich inclusions; b) ultimate strength (MPa); c) elongation at break (\%). 


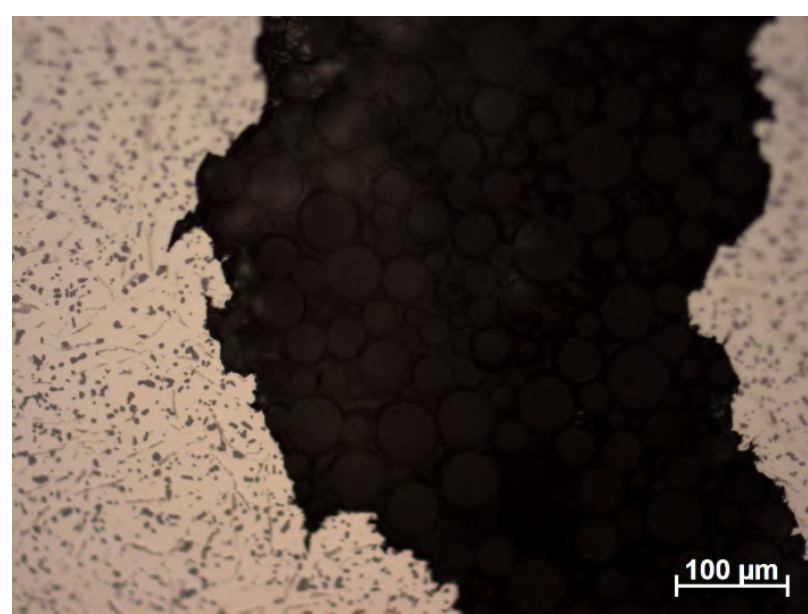

Fig. 17 Fracture surface (cross section) of the heattreated specimen with $2.3 \% \mathrm{Fe}$.

\section{Discussion}

The previous results provide new insights into the understanding of the fatigue behavior of a recycled Al$\mathrm{Si}-\mathrm{Cu}$ alloy and the mechanism of the evolution of the fatigue damage. The $3 \mathrm{D}$ characterization of the fracture surfaces by micro-computed tomography and scanning electron microscopy shows that shrinkage pores and interacting gas pores are the main crack initiation sites of the alloy, what is in good agreement with other studies in this field [13]. Nevertheless, the analysis of nonmachined specimens reveal that the casting skin has a significant influence in the fatigue behavior, since it insulates the material from the air environment and promotes internal crack initiation. The $\beta-\mathrm{Al}_{5} \mathrm{FeSi}$ play a moderate role in the evolution of damage due to the interaction of pores that drive the crack propagation. However, $\beta-\mathrm{Al}_{5} \mathrm{FeSi}$ inclusions located parallel to the crack path can break by splitting through the middle and causing some kinking in the crack path. The cracks propagate through these $\mathrm{B}-\mathrm{Al}_{5} \mathrm{FeSi}$ particles until they reach the $\mathrm{Al}$ matrix, and stress relaxation occurs at the crack tip.

The strain localizations at conveniently oriented hard eutectic Si has a similar effect on the crack path. These findings imply that the strain localizations at $\mathrm{B}-\mathrm{Al}_{5} \mathrm{FeSi}$ and eutectic Si particles could also drive the growth of other secondary microcracks initiated from shrinkage and gas pores and cause the coalescence at advanced stages of damage. Heat treatment did not affect the crack initiation mechanism since it is fully dominated by the interaction of shrinkage and gas pores, which remain after subjecting the specimens to heat treatment. However, the fragmentation and dissolution of the $\beta$ $\mathrm{Al}_{5} \mathrm{FeSi}$ particles (see Fig. 17) can alter the mechanism of the crack growth, particularly in the alloy with increased Fe content. This implies that there is a distinct effect of the Fe-content on the crack growth phase. However, this will not be seen in the lifetimes of fatigue specimens, as crack interaction of pore-initiated cracks competes with crack kinking caused by hard phases.

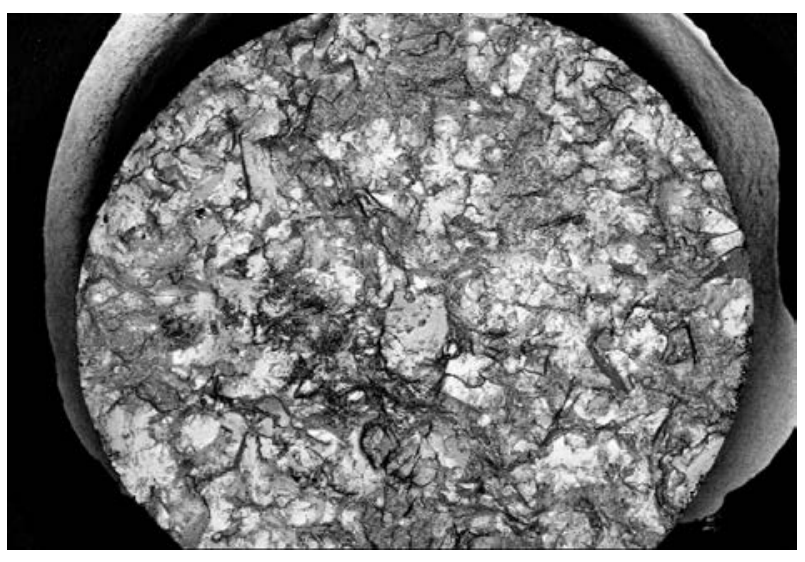

a)

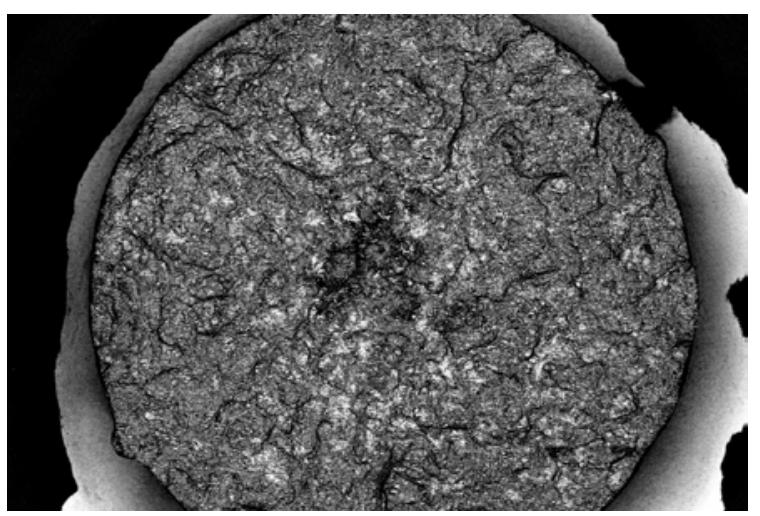

b)

Fig. 17 a) Fracture surfaces of the tensile specimens with $1.85 \% \mathrm{Fe}$ content before and $\mathrm{b}$ ) after heat treatment.

\section{Conclusions}

The effect of the casting defects in a recycled Al-Si-Cu alloy on the fatigue damage evolution was analysed by micro-computed tomography and scanning electron microscopy. Based on the results, the following conclusions may be drawn:

1) A high dispersion in size and morphology of the defects was found due to the variation of the cooling rate during casting. Different defect cases led to various damage scenarios that were monitored and classified. The cast skin can insulated the crack propagation and enabled the crack initiation from the inner part of the material.

2) The interaction between shrinkage and gas pores located at the inter-dendritic spaces was the main cause of crack initiation. The hard particles such as eutectic Si particles and $\mathrm{B}-\mathrm{Al}_{5} \mathrm{FeSi}$ plates did not play any role in the crack initiation process.

3) $\mathrm{B}-\mathrm{Al}_{5} \mathrm{FeSi}$ plates and $\mathrm{Cu}$-rich particles located parallel to the crack broke through the middle driving the crack propagation at some stages. However, this mechanism did not affect the lifetimes under fatigue loading. 
4) The size of the $\beta-\mathrm{Al}_{5} \mathrm{FeSi}$ inclusions increased exponentially with the Fe-content, what caused a deep reduction of the ultimate strength and the ductility of the alloy.

5) Heat treatment partially fragmented and dissolved the $\mathrm{B}-\mathrm{Al}_{5} \mathrm{FeSi}$ particles, although the effect is limited in the alloy with high Fe-content.

\section{Acknowledgments}

The authors would like to thank the Hessen State Ministry of Higher Education, Research and the Arts Initiative for the Development of Scientific and Economic Excellence (LOEWE) - for financial support of the special research project "Safer Materials".

\section{References}

1. P.D. Lee, T.C. Lindley, C.W.J. Cheong, G.R. Davis, J. Elliot. Proceeding of COM, Vancouver, BC, 2003, p.457.

2. S.K. Das, J.A.S. Green. Aluminum industry and climate change assessment and responses. JOM (2010), 62 (2), 27-31.

3. EEA/OEA Recycling Division. Aluminum recycling in Europe. European Aluminum 2007, 1, 51.

4. N. Vanderess, E. Maire, A. Chabod, J-Y Buffière. Microtomographic study and finite element analysis of the porosity harmfulness in a cast aluminium alloy. Int J Fatigue (2011), 33, 1514-25.

5. I. Bacaicoa, M. Luetje, M. Wicke, A. Brueckner-Foit. Characterization of Casting Pores in Fe-rich Al-Si-Cu Alloys by Microtomography and Finite Element Analysis. Procedia Structural Integrity (2016) 2, 2269-2276.

6. L. Wang, N. Limodin, A. El Bartali, J.-F. Witz, R. Seghir, J.-Y. Buffiere, E. Charkuk. Influence of pores on crack initiation in monotonic tensile and cyclic loadings in lost foam casting A319 alloy by using 3D in-situ analysis. Mater. Sci. \& Eng. A (2016), vol. 673, pp. 362-372.

7. I. Bacaicoa, M. Luetje, M. Wicke, A. Geisert, M. Fehlbier, A, Brueckner-Foit. Characterization of casting defects in Fe-rich Al-Si-Cu Alloys by Microtomography and Finite Element Analysis. Engng. Fract. Mech. (2017), 183, 159-169.
8. I. Bacaicoa, I., Luetje, M., Wicke, M., Geisert, A., Zeismann, F., Fehlbier, M., Brueckner-Foit, A. (2016). 3D Morphology of Al5FeSi inclusions in high Fe-content Al-Si-Cu Alloys. Procedia Structural Integrity, vol. 2. pp. 2269-2276.

9. M. Luetje, I. Bacaicoa, M. Wicke, A. Geisert, M. Fehlbier, A.Brueckner-Foit(2017). 3D characterization of fatigue damage mechanism in a cast aluminum alloy using X-ray tomography. International Journal of Fatigue, vol. 103, pp. 363370 .

10. I. Bacaicoa, P.K. Dwivedi, M. Luetje, F. Zesimann, A. Geisert, A. Brueckner-Foit, M. Fehlbier. Effect of non-equilibrium heat treatments on the microstructure and tensile prioperties of an Al-Si-Cu alloy. Materials Science and Engineering A (2016), vol. 673, 562-571.

11. P. Ashtari, H. Tezuka, T. Sato. Influence oft he Sr and $\mathrm{Mn}$ additions on intermetallic compound morphologies in Al-SI-Cu-Fe cast alloys. Mater. Trans. (2003), 44 (12), 2161-2174.

12.FEI Company. Avizo 3D Software. https://www.fei.com/software/amira-avizo (2016), 9.2.

13. Z. Li, N. Limodin, A. Tandjaoui, P. Quaegebeur, P. Osmond, D. Balloy. Influence of $\mathrm{Sr}, \mathrm{Fe}$ and $\mathrm{Mn}$ content and casting process on the microstructures and mechanical properties of $\mathrm{AlSi} 7 \mathrm{Cu} 3$ alloy .Mater. Sci. \& Eng. A. (2017), vol. 24, pp. 286-297. 